\title{
Lateral arthroplasty along with buccal fat pad inter-positioning in the management of Sawhney type III temporomandibular joint ankylosis
}

\author{
Vijay Laxmy Malhotra ${ }^{1}$, Virendra Singh², JK Dayashankara Rao ${ }^{3}$, Sunil Yadav ${ }^{4}$, \\ Pranav Gupta ${ }^{5}$, Radhey Shyam ${ }^{1}$, Shruti Kirti ${ }^{1}$ \\ ${ }^{\prime}$ Department of Dentistry, Shaheed Hasan Khan Mewati (SHKM), Govt. Medical College, Mewat, \\ ${ }^{2}$ Department of Oral and Maxillofacial Surgery, Post Graduate Institute of Medical Sciences (PGIMS), Rohtak, \\ ${ }^{3}$ Department of Oral and Maxillofacial Surgery, SGT Dental College \& Hospitals, Gurgaon, \\ ${ }^{4}$ Department of Dentistry, BPS Govt. Medical College for Women, Sonepat, \\ ${ }^{5}$ Department of Dentistry, Government Medical College, Bharatpur, India
}

\begin{abstract}
J Korean Assoc Oral Maxillofac Surg 2019;45:129-134)
Objectives: The objective of this study was to highlight the role of lateral arthroplasty along with interposition of the buccal fat pad (BFP) in the management of Sawhney type III temporomandibular joint (TMJ) ankylosis.

Materials and Methods: Ten patients with TMJ ankylosis (7 unilateral and 3 bilateral, total of 13 joints) were treated with lateral arthroplasty and BFP interposition. The bony bridge of the ankylotic mass on the lateral aspect was resected, leaving a distance of 1.5 to $2.0 \mathrm{~cm}$ from the base of the skull to the neck of the condyle. The condyle was left intact. Coronoidectomy was performed on the ipsilateral side via the same approach in all cases. The inter-incisal opening was measured at that time, and if it was less than $35 \mathrm{~mm}$, contralateral coronoidectomy was performed by using the intra-oral approach. After satisfactory inter-incisal mouth opening $(\geq 35 \mathrm{~mm})$ was achieved, the TMJ surgical site was revisited, and BFP was retrieved and used to cover the lateral aspect of the medially placed condyle.

Results: With lateral arthroplasty, the medially displaced condyle can be left in-situ to maintain the mandibular ramal height and function and to act as a growth center in children. Interposition of the BFP prevents reformation of the lateral bony bridge that was removed.

Conclusion: Lateral arthroplasty along with interpositioning of the BFP is a novel technique for managing Sawhney type III ankylosis that achieves management goals while avoiding complex and advanced reconstructive surgical procedures.
\end{abstract}

Key words: Temporomandibular joint ankylosis, Lateral arthroplasty, Buccal fat pad, Sawhney type III ankylosis

[paper submitted 2018. 5. 17 / revised 2018. 7. 9 / accepted 2018. 7. 9]

\section{Introduction}

Management of temporomandibular joint (TMJ) ankylosis varies from gap arthroplasty to advanced interpositional arthroplasty and reconstructive procedures. The main objectives for managing TMJ ankylosis are joint function and movement, prevention of relapse, facilitation of normal jaw growth

\section{Vijay Laxmy Malhotra}

Department of Dentistry, Shaheed Hasan Khan Mewati (SHKM), Govt. Medical College, Nuh, Nalhar, Mewat, Haryana 122107, India

TEL: +91-9958310059

E-mail:vijaylaxmy13@yahoo.co.in

ORCID: https://orcid.org/0000-0003-3119-7371

(c) This is an open-access article distributed under the terms of the Creative Commons Attribution Non-Commercial License (http://creativecommons.org/ licenses/by-nc/4.0/), which permits unrestricted non-commercial use, distribution, and reproduction in any medium, provided the original work is properly cited. Copyright (C) 2019 The Korean Association of Oral and Maxillofacial Surgeons. All rights reserved. (particularly in children), and facial aesthetics. In 1986, Sawhney ${ }^{1}$ was the first to classify TMJ ankylosis, dividing it into four types on the basis of anatomical relationships, as shown via computed tomography (CT) of the joint. Type III ankylosis involves an improperly treated or displaced condylar process fracture; in this condition, a clear bridge of bone is present between the ramus and zygomatic arch, and after the bony bridge is excised, the upper articular surface and the articular disc on the deeper surface are intact. A condyle of reduced size located slightly medial to the normal anatomical position is present and potentially functional ${ }^{1}$. Nitzan et $\mathrm{al}^{2}{ }^{2}$ hypothesized that management of type III cases should involve preservation rather than elimination of both the condyle and disc and that both should fulfill their assigned roles in mandibular function and growth, even with their awkward shape and medial position. In patients with type III ankylosis, 
the objectives of TMJ surgery can be achieved by using the novel and simple technique of lateral arthroplasty along with buccal fat pad (BFP) interpositioning, thus avoiding complex and advanced reconstructive procedures. The goal of this surgical procedure is to attain a well-functioning short condyle in a medial location after resection of the lateral bony ankylotic mass. The BFP interpositioned on the lateral aspect prevents reformation of the lateral bony bridge.

\section{Materials and Methods}

A retrospective study was performed of 10 patients with TMJ ankylosis (7 unilateral and 3 bilateral; 13 joints) who were confirmed as having Sawhney type III ankylosis using coronal sections of cone-beam computed tomography (CBCT) and were treated with lateral arthroplasty and BFP interposition in the Department of Dentistry, Shaheed Hasan Khan Mewati (SHKM), Govt. Medical College (Mewat, India), between 2013 to 2016. This retrospective chart review was

Table 1. Demographic and clinical characteristics of patients

\begin{tabular}{|c|c|c|c|c|c|c|c|c|c|c|}
\hline \multirow{2}{*}{$\begin{array}{l}\text { Patient } \\
\text { No. }\end{array}$} & \multirow{2}{*}{$\begin{array}{c}\text { Age } \\
(y r) / s e x\end{array}$} & \multirow{2}{*}{$\begin{array}{c}\text { Side of } \\
\text { ankylosis }\end{array}$} & \multirow{2}{*}{$\begin{array}{l}\text { Duration of } \\
\text { ankylosis } \\
(\mathrm{yr})\end{array}$} & \multirow{2}{*}{$\begin{array}{c}\text { Etiology } \\
\text { of ankylosis }\end{array}$} & \multicolumn{2}{|c|}{$\begin{array}{c}\text { Mouth } \\
\text { opening }(\mathrm{mm})\end{array}$} & \multirow[t]{2}{*}{ Last $\mathrm{F} / \mathrm{U}$} & \multirow[t]{2}{*}{ Complications } & \multirow{2}{*}{$\begin{array}{l}\text { Facial nerve } \\
\text { function }\end{array}$} & \multirow[t]{2}{*}{ Coronoidectomy } \\
\hline & & & & & Preop & $\mathrm{F} / \mathrm{U}$ & & & & \\
\hline 1 & $10 / \mathrm{F}$ & Left & 4 & $\begin{array}{c}\text { Fall from } \\
\text { height }\end{array}$ & 4 & 35 & $2 \mathrm{yr}, 2 \mathrm{mo}$ & $\begin{array}{l}\text { Postoperative } \\
\text { periorbital edema } \\
\text { that resolved in } \\
1 \text { week without } \\
\text { any intervention }\end{array}$ & Normal & Ipsilateral \\
\hline 2 & $15 / \mathrm{M}$ & Right & 10 & $\begin{array}{c}\text { Fall from } \\
\text { height }\end{array}$ & 14 & 34 & $2 \mathrm{yr}, 6 \mathrm{mo}$ & None & Normal & Bilateral \\
\hline 3 & 7/M & Bilateral & 2 & $\begin{array}{c}\text { Fall from } \\
\text { height }\end{array}$ & Nil & 35 & $6 \mathrm{mo}$ & None & Normal & Bilateral \\
\hline 4 & $9 / \mathrm{M}$ & Left & 5 & $\begin{array}{c}\text { Fall from } \\
\text { height }\end{array}$ & 4 & 32 & $8 \mathrm{mo}$ & None & Normal & Bilateral \\
\hline 5 & $12 / \mathrm{F}$ & Bilateral & 6 & $\begin{array}{c}\text { Fall from } \\
\text { height }\end{array}$ & 8 & 36 & $1 \mathrm{yr}$ & None & Normal & Bilateral \\
\hline 6 & $15 / \mathrm{F}$ & Right & 8 & $\begin{array}{l}\text { Fall of heavy } \\
\text { object (door) } \\
\text { on the face }\end{array}$ & 4 & 34 & $1 \mathrm{yr}, 1 \mathrm{mo}$ & None & Normal & Bilateral \\
\hline 7 & $16 / \mathrm{F}$ & Bilateral & 6 & $\begin{array}{l}\text { Fall from } \\
\text { height }\end{array}$ & Nil & 30 & $2 \mathrm{yr}, 5 \mathrm{mo}$ & None & Normal & Bilateral \\
\hline 8 & $12 / \mathrm{F}$ & Right & 5 & $\begin{array}{c}\text { Fall from } \\
\text { height }\end{array}$ & Nil & 40 & $2 \mathrm{yr}, 7 \mathrm{mo}$ & None & Normal & Bilateral \\
\hline 9 & $14 / \mathrm{M}$ & Right & 7 & $\begin{array}{c}\text { Fall from } \\
\text { height }\end{array}$ & 3 & 35 & $6 \mathrm{mo}$ & None & Normal & Ipsilateral \\
\hline 10 & $8 / \mathrm{M}$ & Left & 6 & $\begin{array}{c}\text { Fall from } \\
\text { height }\end{array}$ & 13 & 36 & $8 \mathrm{mo}$ & None & $\begin{array}{l}\text { Temporary } \\
\text { weakness of } \\
\text { temporal branch } \\
\text { of facial nerve }\end{array}$ & Bilateral \\
\hline
\end{tabular}

(F: female, M: male, Preop: preoperative, F/U: follow-up)

Vijay Laxmy Malhotra et al: Lateral arthroplasty along with buccal fat pad inter-positioning in the management of Sawhney type III temporomandibular joint ankylosis. J Korean Assoc Oral Maxillofac Surg 2019
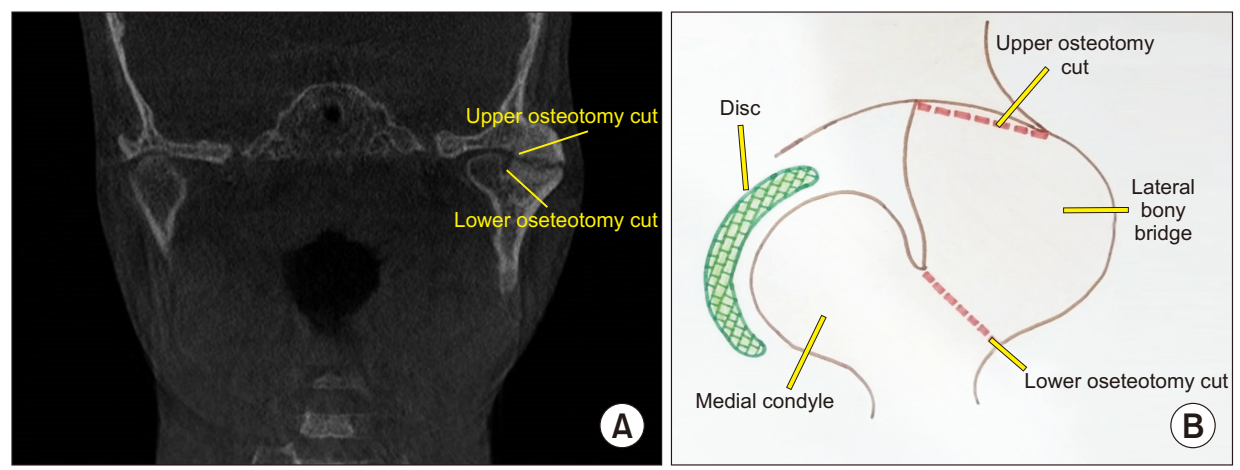

Fig. 1. A. Preoperative coronal conebeam computed tomography image showing Sawhney type III ankylosis. B. Sawhney type III TMJ ankylosis.

Vijay Laxmy Malhotra et al: Lateral arthroplasty along with buccal fat pad inter-positioning in the management of Sawhney type III temporomandibular joint ankylosis. J Korean Assoc Oral Maxillofac Surg 2019 
exempted from institutional review board approval. In all patients, various demographic and clinical information was recorded.(Table 1) Patients with a history of previous TMJ surgery were excluded.

Coronal sections of the CBCT were used to orient the surgeon regarding the angulation and design of the osteotomy, ensuring that the medially placed condyle and disc were not damaged.(Fig. 1. A) All surgical procedures were performed under general anesthesia, and a fiber optic endoscope was used for nasal intubation. The bony bridge of the ankylotic mass on the lateral aspect was resected, leaving a distance of 1.5 to $2.0 \mathrm{~cm}$ from the base of the skull to the neck of the condyle.(Fig. 2. A) The condyle was left intact.(Fig. 2, 3) Coronoidectomy was performed on the ipsilateral side through the same approach in all cases. The inter-incisal opening was measured at that time, and if it was less than $35 \mathrm{~mm}$, contralateral coronoidectomy was performed with an intra-oral approach. After satisfactory inter-incisal mouth opening ( $\geq 35 \mathrm{~mm}$ ) was achieved, the TMJ surgical site was revisited, and the BFP was retrieved and used to cover the lateral aspect of the medially placed condyle.(Fig. 4. A) The BFP was sutured to the soft tissue covering the anterior aspect of the external auditory meatus. The surgical site was then closed as conventional.

Aggressive physiotherapy was started from the first postoperative day with the help of Heister's mouth opener (provided to each patient). The patients were asked to use the device for 5 minutes every hour while awake, every day. The patients were also asked to chew gum 8 to 10 times a day. These exercises were continued for 3 months.

\section{Results}

The present study included 10 patients with a mean age of 11.8 years (range, 8-16 years); there were 5 males and 5 females. Trauma was the etiological factor in all patients. Bilateral coronoidectomy was performed in 8 cases, and unilateral coronoidectomy was performed in 2 cases. The BFP was harvested and interpositioned in all cases. The mean preoperative maximum inter-incisal mouth opening (MIMO) was $5 \mathrm{~mm}$ (range, 0-14 mm). The mean MIMO at the last follow-up was $34.7 \mathrm{~mm}$ (range, 30-40 $\mathrm{mm}$ ). None of the patients complained of any pain while chewing or at rest at the last follow-up. All patients were satisfied with their results. No signs of facial paresis were present in any patients at the last follow-up. At 6 months after surgery, all patients were advised to undergo CBCT scans. The scans showed a wellmaintained intra-articular space in all patients.(Fig. 2)

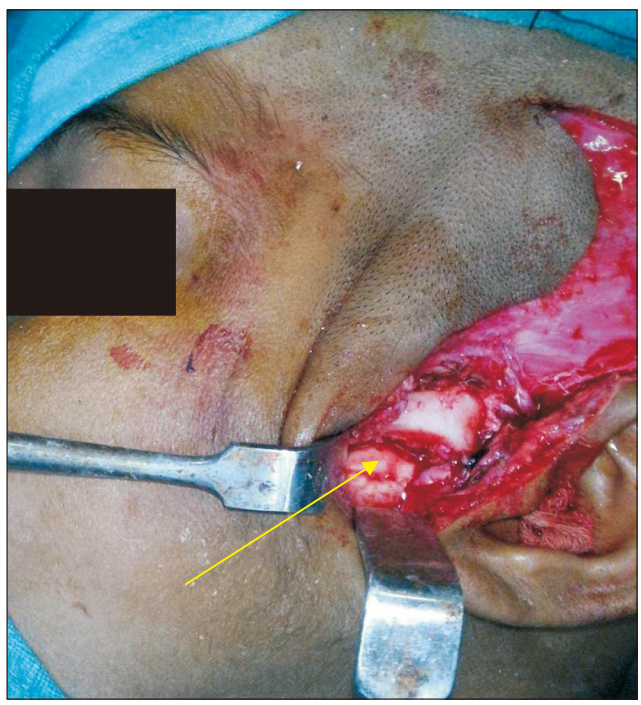

Fig. 3. Intraoperative photograph showing medially preserved condyle (arrow).

Vijay Laxmy Malhotra et al: Lateral arthroplasty along with buccal fat pad interpositioning in the management of Sawhney type III temporomandibular joint ankylosis. $J$ Korean Assoc Oral Maxillofac Surg 2019
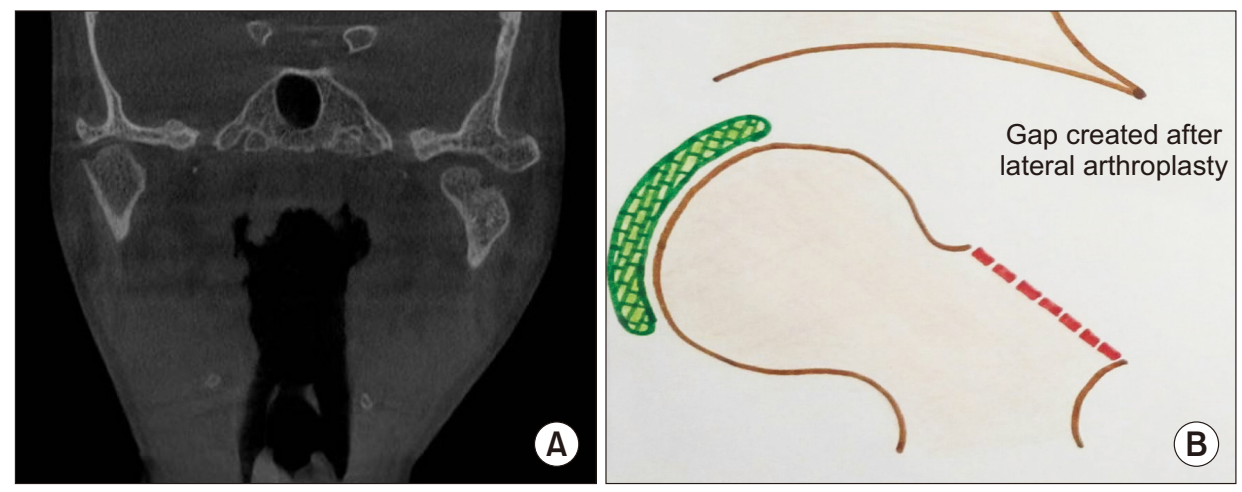

Fig. 2. A. Postoperative coronal conebeam computed tomography image showing lateral arthroplasty. B. Gap created after removal of lateral bony bridge.

Vijay Laxmy Malhotra et al: Lateral arthroplasty along with buccal fat pad inter-positioning in the management of Sawhney type III temporomandibular joint ankylosis. J Korean Assoc Oral Maxillofac Surg 2019 

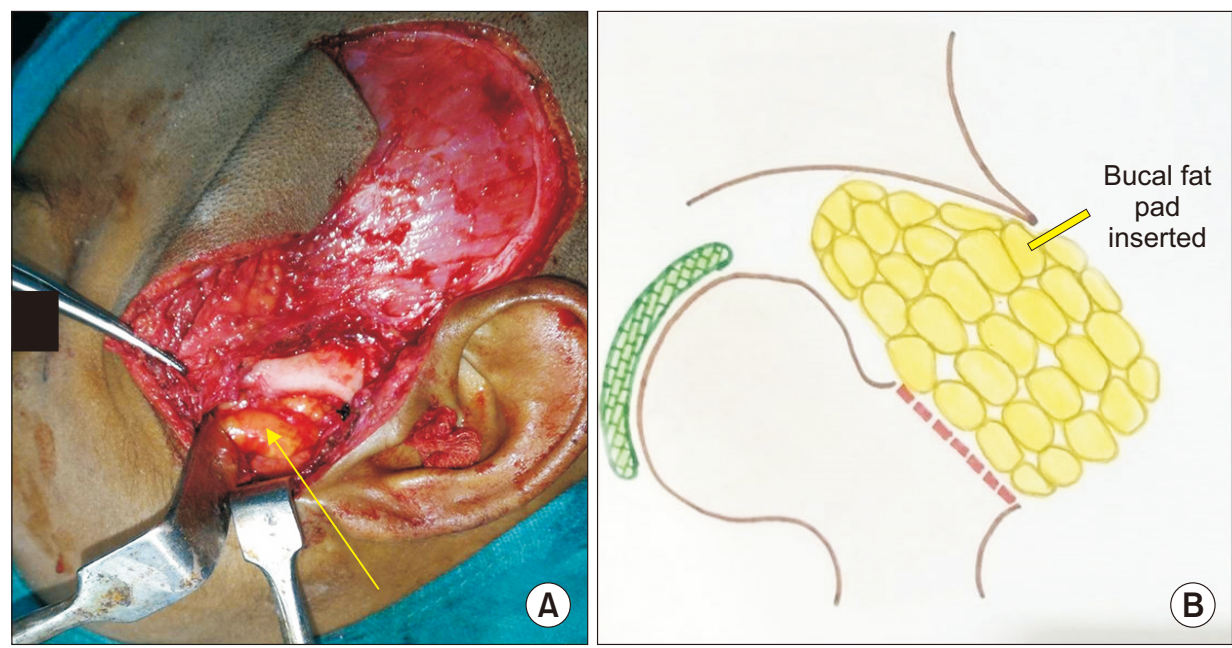

Fig. 4. A. Intraoperative photograph showing buccal fat pad (BFP) interpositioning (arrow). B. BFP inserted on lateral aspect of condyle.

Vijay Laxmy Malhotra et al: Lateral arthroplasty along with buccal fat pad inter-positioning in the management of Sawhney type III temporomandibular joint ankylosis. J Korean Assoc Oral Maxillofac Surg 2019

\section{Discussion}

Multiple operative procedures are used to manage TMJ ankylosis, but none are universally accepted. Operative procedures include gap arthroplasty with or without interpositional grafts; and resection of the ankylotic mass and reconstruction of the ramus-condyle unit with autogenous or alloplastic grafts $^{3}$. In a study of 791 cases of TMJ ankylosis, Mehrotra et al. ${ }^{4}$ concluded that sternoclavicular graft reconstruction in children and dermal fat interposition arthroplasty in adults should be the treatment of choice for the management of TMJ ankylosis. In a variety of studies, gap or interpositional arthroplasty has been performed for TMJ type III ankylosis. Zhi et al. ${ }^{5}$ treated 19 cases of type III ankylosis with gap or interpositional arthroplasty. Elgazzar et al. ${ }^{6}$ treated 101 cases of ankylosis with gap or interpositional arthroplasty, and Dimitroulis ${ }^{7}$, in a retrospective study, presented the clinical experience of using a dermis-fat interpositional graft in the surgical management of TMJ ankylosis in 11 adult patients. None of these studies provided a description of the type of ankylosis. All patients in these studies underwent the same treatment strategy; no adaptations were made for type III cases.

When the condylar process is fractured below the insertion of the lateral pterygoid muscle, it is displaced along with pterygoid muscle in an antero-inferio-medial direction. This type of trauma is treated either by open or closed reduction, but in children, the condition is usually managed conservatively ${ }^{8}$.

In closed treatment, maxilla-mandibular fixation for 10 to14 days is used to re-establish normal occlusion, followed by intensive physiotherapy for rehabilitation of normal sym- metrical mandibular movement. During the period of repeated exercises, the stump with the attached medially displaced condyle grows and remodels in young individuals, creating a double hump-shaped condyle that can perform all mandibular movements and functions normally as a site of growth ${ }^{8}$.

Improper treatment of a displaced condylar process fracture results in the stump ankylosing to the fossa, producing type III ankylosis. In India, because of negligence and parents' lack of awareness, these cases are not typically treated at an early stage, making such clinical situations more common ${ }^{8}$.

Preoperative diagnosis of TMJ ankylosis with the help of CBCT (coronal view) is very important to detect Sawhney type III cases. Although CT is a standard investigative procedure for TMJ ankylosis, clinicians working in resource-scarce environments may rely on plain radiographs alone ${ }^{9}$. However, plain radiographs alone cannot detect Sawhney type III cases, and as a result, these cases are managed improperly as type IV cases. The importance of getting a preoperative CT or CBCT scan cannot be over-emphasized".

In type III ankylosis where CBCT clearly shows a medially displaced condyle and a lateral bony bridge, one should try to preserve the condyle rather than eliminating it because advanced reconstructive surgical procedures are required when both the condyle and disc cannot be retained. Although located in an awkward position, the medially displaced condyle should function exactly as it would after a properly treated displaced condylar fracture. In type III ankylosis, reconstruction is not required because the medially displaced condyle maintains the ramus height even after lateral arthroplasty ${ }^{8}$. To prevent reformation of the lateral bony bridge, the BFP is positioned lateral to the medially displaced condyle. This placement of the BFP not only helps in achieving haemostasis by 
reducing dead space, but also acts as a barrier in reformation of the lateral bony bridge, thus preventing re-ankylosis.

Harvold et al. ${ }^{10}$, in treating hemifacial microsomia, argued that even a deformed condyle shows function and growth when released, and therefore, the condyle and disc should be used rather than eliminated and replaced with a suboptimal solution. Caldwell ${ }^{11}$ maintained that restoration of joint function at an early age, rather than removal of the condyle, is necessary to activate as much growth potential as possible.

In a study of 15 patients, Singh et al. ${ }^{8}$ concluded that lateral arthroplasty is the treatment of choice in Sawhney type III TMJ ankylosis and aggressive resection of the ankylosed joints is strongly contraindicated in these cases. Compared to surgical procedures that require complete resection of the ankylotic mass, lateral arthroplasty has many advantages. First, removal of the medially displaced condylar stump increases the risk of injury to deep vessels, which can cause intraoperative hemorrhage. Since lateral arthroplasty involves removal of the superficial bony bridge only, the risk of injury to deep vessels is very small. Second, lateral arthroplasty is associated with reduced postoperative discomfort and a faster recovery because the procedure is less traumatic. Third, as there is no need for joint reconstruction, the operative time is reduced, and thus, the time for which the patient requires general anesthesia is also reduced.

On the other hand, if the condylar stump is completely resected, joint reconstruction is required, especially in cases of bilateral TMJ ankylosis, in order to maintain the vertical height of the ramus and avoid an anterior open bite in occlusion. In such cases, opting for TMJ reconstruction with autogenous grafts such as costochondral or sternoclavicular grafts will lead to additional surgical site morbidity. Alternatively, opting for alloplastic TMJ reconstruction will lead to an additional financial burden for patients. In bilateral TMJ ankylosis, these additional problems can be avoided, even if one is able to perform lateral arthroplasty on only one side.

The first clinical use of the BFP was described by Egyedi ${ }^{12}$ in 1977. There was a time when the BFP was considered a surgical nuisance ${ }^{13-15}$. However, use of the BFP has become a preferred option in oral and maxillofacial applications because of its relative ease of use, anatomically favorable position, minimal dissection required for harvesting, and low rate of failure ${ }^{16}$.

The BFP is a simple lobulated mass consisting of a central body and four extensions: buccal, pterygoid, pterygopalatine, and temporal. The body consists of three different lobes: anterior, intermediate, and posterior. Each lobe is encapsulated by an independent membrane and separated by a natural space ${ }^{17}$. The mean volume of the BFP is 10 square centimeter ${ }^{18}$. Regardless of overall body weight and fat distribution, the size of the BFP is fairly constant. Even in cachectic patients, the $\mathrm{BFP}$ is of normal weight and volume ${ }^{19}$.

The success of using the BFP is attributed to its rich vascular supply, reduced donor site morbidity, ease of harvest, and low rate of complications ${ }^{20}$. Although rare, complications associated with use of the BFP include complete or partial loss of the flap, limitation of mouth opening, hematoma, hemorrhage, postoperative infection, and depressed cheek ${ }^{21-24}$. None of these rare complications were encountered in our study.

Rattan $^{17}$ used the BFP as a useful adjunct to autologous or alloplastic TMJ reconstruction after ankylosis release. Singh et al. ${ }^{25}$ evaluated the usefulness and feasibility of the BFP as an interposition graft in the treatment of TMJ ankylosis and found it successful. Gagnani et al. ${ }^{26}$ have advocated for use of the BFP for interposition after gap arthroplasty. According to a literature review by Singh et al. ${ }^{16}$, elimination of dead space is the main goal in TMJ operations. The BFP helps in achieving this goal. In addition, isolation of the joint by the BFP reduces the risk of formation of fibrosis and bone in the area. Gaba et al. ${ }^{27}$ used magnetic resonance imaging to assess the fate of the BFP when used as an interpositional graft in TMJ ankylosis. They concluded that the BFP is viable after 1 year and prevents heterotopic bone formation after TMJ ankylosis release.

In our experience, BFP interposition on the lateral aspect of the medially displaced condyle after lateral arthroplasty in type III ankylosis is a simple and effective method for managing this condition. The treatment is also less traumatic than autogenous joint reconstruction and more cost efficient than alloplastic reconstructive procedures.

\section{Conclusion}

In Sawhney type III ankylosis treated with lateral arthroplasty, the medially displaced condyle can be left in situ to maintain the mandibular ramal height and function and to act as a growth center in children. The presence of the BFP prevents reformation of the lateral bony bridge.

\section{ORCID}

Vijay Laxmy Malhotra, https://orcid.org/0000-0003-3119-7371

Virendra Singh, https://orcid.org/0000-0002-7295-5514

JK Dayashankara Rao, https://orcid.org/0000-0001-7448-195X 
Sunil Yadav, https://orcid.org/0000-0001-6669-1279

Pranav Gupta, https://orcid.org/0000-0003-1218-5199

Radhey Shyam, https://orcid.org/0000-0001-5758-3540

Shruti Kirti, https://orcid.org/0000-0001-7181-8625

\section{Authors' Contributions}

V.L.M. did the data collection and wrote the manuscript. V.S., J.K.D.R., and S.Y. played a role in study design and coordination. P.G. and S.K. drafted the manuscript. R.S. helped in statistical analysis.

\section{Ethics Approval and Consent to Participate}

This study was a retrospective chart review, and it was exempted from institutional review board approval.

\section{Consent for Publishing Photographs}

Written informed consent was obtained from the patients for publication of this article and accompanying images.

\section{Conflict of Interest}

No potential conflict of interest relevant to this article was reported.

\section{References}

1. Sawhney CP. Bony ankylosis of the temporomandibular joint: follow-up of 70 patients treated with arthroplasty and acrylic spacer interposition. Plast Reconstr Surg 1986;77:29-40.

2. Nitzan DW, Bar-Ziv J, Shteyer A. Surgical management of temporomandibular joint ankylosis type III by retaining the displaced condyle and disc. J Oral Maxillofac Surg 1998;56:1133-8; discussion 1139.

3. Loveless TP, Bjornland T, Dodson TB, Keith DA. Efficacy of temporomandibular joint ankylosis surgical treatment. J Oral Maxillofac Surg 2010;68:1276-82.

4. Mehrotra D, Pradhan R, Mohammad S, Kumar S. Complications associated with different surgical modalities for management of temporomandibular ankylosis in a series of 791 cases. Asian J Oral Maxillofac Surg 2011;23:122-7.

5. Zhi K, Ren W, Zhou H, Gao L, Zhao L, Hou C, et al. Management of temporomandibular joint ankylosis: 11 years' clinical experience. Oral Surg Oral Med Oral Pathol Oral Radiol Endod 2009;108:687-92.

6. Elgazzar RF, Abdelhady AI, Saad KA, Elshaal MA, Hussain MM, Abdelal SE, et al. Treatment modalities of TMJ ankylosis: experience in Delta Nile, Egypt. Int J Oral Maxillofac Surg 2010;39:333-42.

7. Dimitroulis G. The interpositional dermis-fat graft in the management of temporomandibular joint ankylosis. Int J Oral Maxillofac Surg 2004;33:755-60.

8. Singh V, Bhagol A, Dhingra R, Kumar P, Sharma N, Singhal R. Management of temporomandibular joint ankylosis type III: lateral arthroplasty as a treatment of choice. Int J Oral Maxillofac Surg 2014;43:460-4.

9. Braimah R, Taiwo A, Ibikunle A, Oladejo T, Adeyemi M, Adejobi F, et al. Clinical experience in managing temporomandibular joint ankylosis: five-year appraisal in a Nigerian subpopulation. J Korean Assoc Oral Maxillofac Surg 2018;44:112-9.

10. Harvold EP, Vargervik K, Chierici G. Treatment of hemifacial microsomia. New York: A.R. Liss; 1983.

11. Caldwell JB. Surgical management of temporomandibular joint ankylosis in children. Int J Oral Surg 1978;7:354-9.

12. Egyedi P. Utilization of the buccal fat pad for closure of oro-antral and/or oro-nasal communications. J Maxillofac Surg 1977;5:241-4.

13. Messenger KL, Cloyd W. Traumatic herniation of the buccal fat pad. Report of a case. Oral Surg Oral Med Oral Pathol 1977;43:41-3.

14. Wolford DG, Stapleford RG, Forte RA, Heath M. Traumatic herniation of the buccal fat pad: report of case. J Am Dent Assoc 1981;103:593-4.

15. Scott P, Fabbroni G, Mitchell DA. The buccal fat pad in the closure of oro-antral communications: an illustrated guide. Dent Update 2004;31:363-4, 366.

16. Singh J, Prasad K, Lalitha RM, Ranganath K. Buccal pad of fat and its applications in oral and maxillofacial surgery: a review of published literature (February) 2004 to (July) 2009. Oral Surg Oral Med Oral Pathol Oral Radiol Endod 2010;110:698-705.

17. Rattan V. A simple technique for use of buccal pad of fat in temporomandibular joint reconstruction. J Oral Maxillofac Surg 2006;64:1447-51.

18. Xiao H, Bayramiçli M, Jackson IT. Volumetric analysis of the buccal fat pad. Eur J Plast Surg 1999;22:177-80.

19. Baumann A, Ewers R. Application of the buccal fat pad in oral reconstruction. J Oral Maxillofac Surg 2000;58:389-92; discussion 392-3.

20. Adeyemo WL, Ogunlewe MO, Ladeinde AL, James O. Closure of oro-antral fistula with pedicled buccal fat pad. A case report and review of literature. Afr J Oral Health 2004;1:42-6.

21. Colella G, Tartaro G, Giudice A. The buccal fat pad in oral reconstruction. Br J Plast Surg 2004;57:326-9.

22. Chakrabarti J, Tekriwal R, Ganguli A, Ghosh S, Mishra PK. Pedicled buccal fat pad flap for intraoral malignant defects: a series of 29 cases. Indian J Plast Surg 2009;42:36-42.

23. Chien CY, Hwang CF, Chuang HC, Jeng SF, Su CY. Comparison of radial forearm free flap, pedicled buccal fat pad flap and splitthickness skin graft in reconstruction of buccal mucosal defect. Oral Oncol 2005;41:694-7.

24. Liu YM, Chen GF, Yan JL, Zhao SF, Zhang WM, Zhao S, et al. Functional reconstruction of maxilla with pedicled buccal fat pad flap, prefabricated titanium mesh and autologous bone grafts. Int $\mathrm{J}$ Oral Maxillofac Surg 2006;35:1108-13.

25. Singh V, Dhingra R, Sharma B, Bhagol A, Kumar P. Retrospective analysis of use of buccal fat pad as an interpositional graft in temporomandibular joint ankylosis: preliminary study. J Oral Maxillofac Surg 2011;69:2530-6.

26. Gagnani SP, Agarwal B, Bhutia O, Roychoudhury A. New method of harvesting a buccal fat pad for interposition after gap arthroplasty of the temporomandibular joint. Br J Oral Maxillofac Surg 2016;54:469-70.

27. Gaba S, Sharma RK, Rattan V, Khandelwal N. The long-term fate of pedicled buccal pad fat used for interpositional arthroplasty in TMJ ankylosis. J Plast Reconstr Aesthet Surg 2012;65:1468-73.

How to cite this article: Malhotra VL, Singh V, Rao JKD, Yadav S, Gupta P, Shyam R, et al. Lateral arthroplasty along with buccal fat pad inter-positioning in the management of Sawhney type III temporomandibular joint ankylosis. J Korean Assoc Oral Maxillofac Surg 2019;45:129-34. https://doi.org/10.5125/jkaoms.2019.45.3.129 